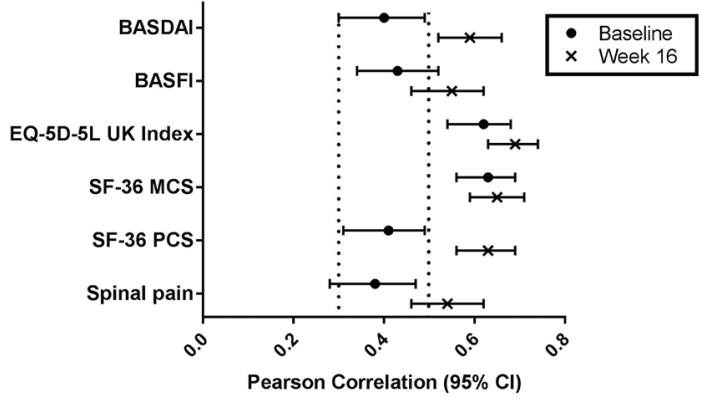

Magnitude of correlation is presented without regard for directionality. Correlation for moderate $(>0.3)$ and high $(>0.5)$.

Abbreviations: MCS=mental component summary; PCS = physical component summary; $\mathrm{SF}-36=36$-item short-form health survey *Cohen,

Figure. Correlation between ASAS-HI and other health measures

Table. Association between ASAS HI Change from Baseline and Disease Activity at Wk 16 (Pooled Treatment Groups)

\begin{tabular}{|c|c|c|c|}
\hline & $\begin{array}{c}\text { ASAS20 } \\
\text { Nonresponder }\end{array}$ & $\begin{array}{c}\text { Patient Achieving ASAS20, } \\
\text { but Not ASAS40 }\end{array}$ & $\begin{array}{l}\text { ASAS40 } \\
\text { Responder }\end{array}$ \\
\hline $\mathrm{N}$ & 181 & 60 & 72 \\
\hline \multirow{2}{*}{$\begin{array}{l}\text { ASAS HI } \\
\text { (LSM [SE]) }\end{array}$} & $-0.3(0.21)$ & $-1.9(0.37)^{\star \star *}$ & $-4.2(0.34)^{\star \star *}, \S$ \\
\hline & $\begin{array}{c}\text { ASDAS } \\
\text { Improvement }<1.1\end{array}$ & $\begin{array}{c}\text { ASDAS Improvement } \geq 1.1 \text { but } \\
<2.0 \\
\text { (clinically important } \\
\text { improvement) }\end{array}$ & $\begin{array}{c}\text { ASDAS } \\
\text { Improvement } \\
\geq 2.0 \\
\text { (major } \\
\text { improvement) }\end{array}$ \\
\hline $\mathrm{N}$ & 196 & 74 & 43 \\
\hline \multirow{2}{*}{$\begin{array}{l}\text { ASAS HI } \\
(\text { LSM [SE]) }\end{array}$} & $-0.4(0.20)$ & $-2.8(0.33)^{\star \star \star}$ & $-4.6(0.43)^{\star \star \star}, \S$ \\
\hline & $\begin{array}{l}\text { BASDAI } 50 \\
\text { Nonresponder }\end{array}$ & $\begin{array}{l}\text { BASDAI } 50 \\
\text { Responder }\end{array}$ & \\
\hline $\mathrm{N}$ & 255 & 58 & \\
\hline $\begin{array}{l}\text { ASAS HI } \\
\text { (LSM [SE]) }\end{array}$ & $-0.8(0.18)$ & $-4.6(0.38)^{\star \star \star}$ & \\
\hline
\end{tabular}

ASDAS = AS Disease Activity Score; BASDAI = Bath Ankylosing Spondylitis Disease

Activity Index; LSM = least squares mean

${ }^{\star \star *} p<.001$ versus lowest response group; $\S p<.001$ versus middle response group.

Note: An ANCOVA model with change in ASAS HI score as dependent variable and clinical outcome response and baseline ASAS $\mathrm{HI}$ as independent variables was applied. Post hoc comparison was conducted using Scheffé's correction.

Disclosure of Interests: Uta Kiltz Grant/research support from: AbbVie, Chugai, Eli Lilly, Grünenthal, Janssen, MSD, Novartis, Pfizer, Roche, and UCB., Consultant for: AbbVie, Chugai, Eli Lilly, Grünenthal, Janssen, MSD, Novartis, Pfizer, Roche, and UCB., Désirée van der Heijde Consultant for: AbbVie, Amgen, Astellas, AstraZeneca, Bristol-Myers Squibb, Boehringer Ingelheim, Celgene, Daiichi, Eli-Lilly, Galapagos, Gilead, GlaxoSmithKline, Janssen, Merck, Novartis, Pfizer, Regeneron, Roche, Sanofi, Takeda, Union Chimique Belge, Annelies Boonen: None declared, Lianne S. Gensler Grant/research support from: Abbvie, Amgen, UCB Pharma, Consultant for: Novartis, Lilly, Janssen, Theresa Hunter Employee of: Eli Lilly and Company, Kathleen Wyrwich Shareholder of: Eli Lilly and Company, Employee of: Eli Lilly and Company, Yan Dong Shareholder of: Eli Lilly and Company, Employee of: Eli Lilly and Company, Xiaoqi Li Shareholder of: Eli Lilly and Company, Employee of: Eli Lilly and Company, Gaia Gallo Shareholder of: Eli Lilly and Company, Employee of: Eli Lilly and Company, Juergen Braun Shareholder of: AbbVie, BMS, Celgene, Chugai, Merck, Novartis, Pfizer, UCB, Grant/research support from: AbbVie, BMS, Celgene, Chugai, Merck, Novartis, Pfizer, UCB, Grant/research support from: Abbott, Bristol Myers Squibb, Celgene, Celltrion, Chugai, Johnson \& Johnson, MSD, Novartis, Pfizer, Roche, UCB Pharma, Grant/ research support from: AbbVie, BMS, Celgene, Chugai, Merck, Novartis, Pfizer, UCB, Grant/research support from: Abbvie (Abbott), Amgen, Baxter, Biogen, BMS, Boehringer, Celgene, Celltrion, Centocor, Chugai, Hexal, Janssen, Lilly, Medac, MSD (Schering-Plough), Mylan, Mundipharma, Novartis, Pfizer (Wyeth, Hospira), Roche, Sanofi-Aventis and UCB, Consultant for: Abbvie (Abbott), Amgen, Baxter, Biogen, BMS, Boehringer, Celgene, Celltrion, Centocor, Chugai, Hexal, Janssen, Lilly, Medac, MSD (Schering-Plough), Mylan, Mundipharma, Novartis, Pfizer (Wyeth, Hospira), Roche, Sanofi-Aventis and UCB, Consultant for: AbbVie, BMS, Celgene, Chugai, Merck, Novartis, Pfizer, UCB, Consultant for: Abbott, Bristol
Myers Squibb, Celgene, Celltrion, Chugai, Johnson \& Johnson, MSD, Novartis, Pfizer, Roche, UCB Pharma, Speakers bureau: AbbVie, BMS, Celgene, Chugai, Merck, Novartis, Pfizer, UCB, Speakers bureau: Abbvie (Abbott), Amgen, Baxter, Biogen, BMS, Boehringer, Celgene, Celltrion, Centocor, Chugai, Hexal, Janssen, Lilly, Medac, MSD (Schering-Plough), Mylan, Mundipharma, Novartis, Pfizer (Wyeth, Hospira), Roche, SanofiAventis and UCB, Speakers bureau: AbbVie, BMS, Celgene, Chugai, Merck, Novartis, Pfizer, UCB

DOI: 10.1136/annrheumdis-2019-eular.1615

\section{AB1322 DEPRESSION IN ESTABLISHED RHEUMATOID ARTHRITIS; MULTICENTER PROSPECTIVE COHORT STUDY FOR EVALUATION OF JOINT SURGERY ON PATIENT'S REPORTED OUTCOME}

Toshihisa Kojima $^{1}$, Masayo Kojima ${ }^{2}$, Hajime Ishikawa ${ }^{3}$, Sakae Tanaka ${ }^{4}$, Keiichiro Nishida ${ }^{5}$, Nobuhiko Haga ${ }^{6}$, Yukio Masaoka ${ }^{7}$, Jun Hashimoto ${ }^{8}$, Hisaaki Miyahara ${ }^{9}$, Yasuo Niki ${ }^{10}$, Tomoatsu Kimura $^{11}$, Hiromi Oda ${ }^{12}$, Shuji Asai ${ }^{1}$, Koji Funahashi ${ }^{13}$, Naoki Ishiguro ${ }^{1} .{ }^{1}$ Nagoya University Graduate School of Medicine, Orthopedic Surgery and Rheumatology, Nagoya, Japan; ${ }^{2}$ Nagoya City University Graduate School of Medical Sciences, Nagoya, Japan; ${ }^{3}$ Niigata Rheumatic Center, Niigata, Japan; ${ }^{4}$ Faculty of Medicine, The University of Tokyo, Tokyo, Japan; ${ }^{5}$ Okayama University Graduate School of Medicine, Dentistry and Pharmaceutical Sciences, Okayama, Japan; ${ }^{6}$ The University of Tokyo Hospital, Tokyo, Japan; ${ }^{7}$ Yukioka Hospital, Osaka, Japan; ${ }^{8}$ National Hospital Organisation Osaka Minami Medical Center, Kawachinagano, Japan; ${ }^{9}$ National Hospital Organisation Kyushu Medical Center, Fukuoka, Japan; ${ }^{10}$ Keio University School of Medicine, Tokyo, Japan; ${ }^{11}$ University of Toyama, Faculty of Medicine, Toyama, Japan; ${ }^{12}$ Saitama Medical University, Morohongo Moroyama, Japan; ${ }^{13}$ KariyaToyota General Hospital, Kariya, Japan

Background: Loss of physical function is a clinical feature of RA. Total management including reconstructive joint surgery and rehabilitation should be needed for further improvements of physical function for established RA patients. In these days, it is very important to evaluate the effectiveness of joint surgery as well as drug therapy based on patient-reported outcome (PRO).

Objectives: The purpose of this study is to explore the relationship among depression, clinical variables and other PROs including physical function and improving of depressive status with joint surgery.

Methods: Multicenter prospective observational cohort study was conducted among patients who underwent elective joint surgery for RA from April 2012 to March 2016 (Study registration: UMIN000012649) (ref.1). In this study, we collected data at baseline and at 6 or 12 months after the surgery. These data were as follow; age, sex, disease duration, drug therapies, and disease activity (DAS28-CRP), and PRO measures [HAQDI, EQ-5D (QOL), pain VAS and BDI-II (depression)]. Correlation between $\mathrm{BDI}-\mathrm{II}$ and other variables were determined using multiple liner regression analysis with forward stepwise.

Results: Totally, 346 patients before elective joint surgery were analyzed cross-sectionally. Mean age, disease duration, pain(VAS), DAS28, HAQ$\mathrm{DI}, \mathrm{EQ}-5 \mathrm{D}$ and $\mathrm{BDI}-\mathrm{Il}$ were 64.2 years, 17.0 years, $36.2 \mathrm{~mm}, 3.02$, $1.111,0.641$ and 13.0 , respectively. $52.6 \%$ of elective joint surgeries were in upper limbs and $47.4 \%$ were in lower limbs. Multiple liner regression analysis showed that HAQ-DI $[\beta:-0.48, p<0.001]$ pain $\operatorname{VAS}(\beta:-0.26$, $p<0.001)$ and $B D I-I I \quad(\beta:-0.19, \quad p<0.001)$ were independent factors for EQ$5 \mathrm{D}$. Furthermore, HAQ-DI $(\beta: 0.31, p<0.001)$ and pain VAS $(\beta: 0.17$, $p=0.002$ ) had significant impact on BDI-II. Especially, walking ( $\beta$ : 0.12 , $p<0.001)$ and eating $(\beta: 0.16, p=0.005)$ were independent factors for BDIII in HAQ-DI categories. As longitudinal analyses $(n=138)$, mean BDI-II was significantly improved from 12.1 at baseline to 10.5 at last observation (6 or 12 months) after joint surgery in lower limbs (paired t-test, $p<0.001)$. Change in HAQ-DI ( $\beta$ : $0.23, p=0.031)$ had significant impact on that in BDI-II. The improving in walk category $(\beta: 0.21, p=0.012)$ was a relevant factor for improving of BDI-II after the surgery.

Conclusion: Loss of physical function is an important factor for impairment of depressive status as well as QOL in established RA patients. Improving of physical function with joint surgery in lower limbs caused improving of depressive status. Rheumatologists should take the joint surgery into consideration as effective intervention for treatment of established RA patients.

\section{REFERENCES}

[1] Kojima T, et al. Int J Rheum Dis. 2018. doi: 10.1111/1756-185X.13394. Acknowledgement: The registry used in this study was supported by a grant from the Ministry of Health, Labour and Welfare (H2424YN002-00) to Naoki Ishiguro 
Disclosure of Interests: Toshihisa Kojima Grant/research support from: Chugai Pharmaceutical (Investigator Initiated Study), Novartis, Nippon Kayaku, Eli Lilly, Eisai, Speakers bureau: Chugai Pharmaceutical, Takeda Pharmaceutical, Pfizer, Eli Lilly Japan, Bristol Myers Squibb, Ono Pharmaceutical, Daiichi Sankyo, Astelas, UCB, Janssen Pharmaceutical, Tanabe Mitsubishi, Masayo Kojima: None declared, Hajime Ishikawa: None declared, Sakae Tanaka Grant/research support from: KYOCERA Corporation and Asahi Kasei Corporation, Consultant for: Amgen Astellas BioPharma K.K., KYOCERA Corporation, Pfizer and Daiichi Sankyo Co., Ltd., Speakers bureau: Asahi Kasei Corporation, Astellas Pharma Inc, Ayumi Pharmaceutical Corporation, Eisai Co., Ltd., Ono Pharmaceutical Co., Ltd., Daiichi Sankyo Co., Ltd, Taisho Toyama Pharmaceutical Co. Ltd., Mitsubishi Tanabe pharma Corporation, Chugai Pharmaceutical Co. Ltd., Teijin Pharma Ltd., Eli Lilly, Hisamitsu Pharmaceutical Co, Inc. Pfizer, Bristol-Myers., Keiichiro Nishida: None declared, Nobuhiko Haga: None declared, Yukio Masaoka: None declared, Jun Hashimoto: None declared, Hisaaki Miyahara: None declared, Yasuo Niki: None declared, Tomoatsu Kimura: None declared, Hiromi Oda: None declared, Shuji Asa Speakers bureau: AbbVie, Astellas, Bristol-Myers Squibb, Chugai, DaiichiSankyo, Eisai, Janssen, Takeda, and UCB Japan, Koji Funahashi: None declared, Naoki Ishiguro Grant/research support from: AbbVie, Asahi Kasei, Astellas, Chugai, Daiichi-Sankyo, Eisai, Kaken, Mitsubishi Tanabe, Otsuka, Pfizer, Takeda, and Zimmer Biomet, Consultant for: Ono, Speakers bureau: Astellas, Bristol-Myers Squibb, Daiichi-Sankyo, Eli Lilly, Pfizer, and Taisho Toyama

DOI: 10.1136/annrheumdis-2019-eular.1689

\section{AB1323 OSTEOPHYTOSIS PROCESS SUGGEST INVOLVEMENT OF MAST CELLS, REVEALED BY WHOLE TRANSCRIPTOME ANALYSIS OF OSTEOPHYTES FROM KNEE OSTEOARTHRITIS PATIENTS}

Priya Kulkarni ${ }^{1}$, Sulev Koks ${ }^{1}$, Abhay Harsulkar ${ }^{2}$, Aare Martson ${ }^{3} .{ }^{1}$ University of Tartu, Department of Pathophysiology, Tartu, Estonia; ${ }^{2}$ Bharati Vidyapeeth University, Department of Pharmaceutical Biotechnology, Pune, India; ${ }^{3}$ University of Tartu, Department of Traumatology and Orthopedics, Tartu, Estonia

Background: Cartilage-loss is a central pathology of osteoarthritis while synovitis, sub-chondral bone sclerosis and osteophytes (OFs) formation are counted as integral phenomenon. Osteophytosis is a process of OFs formation, in which mesenchymal stem cells from periosteum and synovium, along with a number of cytokines, growth factors and biochemical factors gives out bony out-growth at margin of the affected joint. Although frequently associated, OFs are one of the less focused areas in OA research, particularly from the molecular mechanism point of view, involved in their formation. Also, it is a good ambiguity if OFs is a pathological condition linked with altered biochemical milieu or a functional adaptation for the joint instability.

Objectives: Accounting its importance in clinical $O A$ and the obscure biochemical background, this study strives for a deeper comprehension of molecular mechanism and active pathways, involved in OF formation Methods: We performed whole transcriptome analysis of OFs, collected from six knee OA patients during knee replacement surgery. Non-OF tissue from tibial plateau of the same patient was used as a control. After RNA isolation, RNA-seq was performed using SOLiD 5500W platform and fragment sequencing chemistry. For differential gene expression analysis, non- normalized raw counts were used for the EdgeR package. To find differential transcriptome between OF and control, we used group-wise comparisons where negative binomial fitting was followed by exact test. Finally, RT-PCR of significantly expressed genes was run for trascriptome validation.

Results: After cluster analysis, total 597 genes were significantly expressed between OFs and controls out of which, 323 genes were seen up-regulated ( $\operatorname{LogFC} \geq 2)$ while 274 were down-regulated (LogFC $\leq$ 2). Further, 88 genes showed marked increase $(P<0.01)$; here CPA3, Selectin E, MS4A2, PLA2G2A and CSN1S1 were prominent. Similarly, 23 genes were with a noteworthy down-regulation $(P<0.01)$ and $A P O B$, CADM2, TNEFF2, GNAZ and GABRA2 remained as first five. GO analysis of the best extracted genes indicated significant involvement of ECM proteoglycan, GABA A receptor pathway (Reactome 2016 - homo sapiens_R-HSA-3000178 and R-HSA-977441, respectively), osteoblast and TNF- $\alpha$ signalling pathways (WikiPathways 2016 -homo sapiens WP322 and homo sapiens WP231 respectively). Finally, tracsriptome results were validated using RT-PCR of significantly expressed genes (CPA3, MMP-1, 3 and 13).

Conclusion: Significant expression of CXCL9, 10, 11 and PGR4 indicate chemotaxis and immune cells deployment; outstanding CPA3 and MS4A2 indicate active involvement of mast cells. Accounting a previous knowledge that 'mast cell products' are linked with increased osteoblastic and osteoclastic activity and impose pathological changes in articular and periarticular tissue, marked expressions of MC products or mediators here, enable us to propose an association between MCs and OF. Presence of E-selectin on endothelial cell surface is known to promote adhesion of neutrophils and further release of TNF $\alpha$ and IL1. Expression of PLA2G2A suggests increased prostaglandin synthesis and indicates activation of inflammatory cascade. In conclusion, this transcriptome analysis suggests a significant association of mast cells with osteophytosis. The genes involving chemotaxis, degranulation, cytokinin synthesis mark the initiation of OF. On the other hand, proteases metrixremodelling enzymes may indicate their growth. A host of different signalling molecules denotes involvement of canonical and non-cannonical pathways that warrants further investigations.

Disclosure of Interests: None declared

DOI: 10.1136/annrheumdis-2019-eular.7318

\section{AB1324 MEASUREMENT PROPERTIES OF THE 10-ITEM CONNOR-DAVIDSON RESILIENCE SCALE AMONG PATIENTS WITH TOTAL KNEE REPLACEMENT BASED ON ITEM RESPONSE THEORY}

Ka Keat Lim', Yu Heng Kwan ${ }^{1}$, Seng Jin Yeo², William Yeo ${ }^{3}$, Julian Thumboo ${ }^{4,5}$, David Matchar ${ }^{1,6}$, Ying Ying Leung ${ }^{4,5}$. 'Duke-NUS Medical School, Programme in Health Services and Systems Research, Singapore, Singapore; ${ }^{2}$ Singapore General Hospital, Department of Orthopaedic Surgery, Singapore, Singapore; ${ }^{3}$ Singapore General Hospital, Orthopaedic Diagnostic Centre, Department of Orthopaedic Surgery, Singapore, Singapore; ${ }^{4}$ Singapore General Hospital, Department of Rheumatology and Immunology, Singapore, Singapore; ${ }^{5}$ Duke-NUS Medical School, Singapore, Singapore; ${ }^{6}$ Duke University Medical Center, Department of Medicine (General Internal Medicine), Durham, United States of America

Background: The number of older adults undergoing total knee arthroplasty (TKR) for knee osteoarthritis (OA) has been increasing. While psy chological resilience may have a role in outcomes after TKR[1], no psychological resilience scale has been validated among patients with knee OA.

Objectives: To examine the measurement properties of the 10-item Connor-Davidson Resilience Scale (CD-RISC10) among older adults with knee $\mathrm{OA}$

Methods: Using data from 700 consecutive consented patients with knee OA enlisted for TKR, we examined four measurement properties of CDRISC10. For structural validity, we fitted graded response model (grm) and examined standardized root-mean square residual (SRMR) for unidimensionality, Chi-square p-value for item fit, residual correlation for local independence and item-characteristic curves for monotonicity. For internal consistency, we examined Cronbach's alpha. For construct validity, we hypothesized that CD-RISC10 as a measure of psychological resilience would be moderately correlated (Pearson's R $0.30-0.50$ ) with self-efficacy and mental well-being but weakly correlated (Pearson's $R<0.30$ ) with physical and social well-being (Table 1). For measurement invariance, we examined uniform and non-uniform differential item functioning (DIF) between gender, age group ( $\leq$ median 66 vs $>66$ years), and language (English vs Chinese) and reported the McFadden's $R^{2}$. We used mirt and lordif packages on Rx64 v3.5.1 to examine grm and DIF respectively. We reported the findings based on COnsensus based Standards for the selection of health Measurement Instruments (COSMIN)[2].

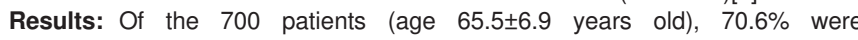
females, $83.9 \%$ Chinese, $55 \%$ responded questionnaire in Chinese. Mean CD-RISC10 score was $27.5 \pm 5.2$, with minimal floor $(0.1 \%)$ and ceiling effects (3.9\%). CD-RISC10 demonstrated unidimensionality (SRMR=0.053) local independence (residual correlation=-0.025), monotonicity (adequate looking item characteristic curves) and internal consistency (Cronbach's alpha $=0.91$ ). Items 1 and 4 had potential misfit (Chi-square $p>0.01$ ). All a-priori hypotheses were met (Table 1). No item had significant DIF with age, gender and language, except item 4 had borderline non-uniform DIF across language (McFadden's $R^{2}=0.03$ ).

Conclusion: We demonstrated structure validity, internal consistency, construct validity and measurement invariance of CD-RISC10 in the measurement of psychological resilience among older adults with knee OA.

\section{REFERENCES}

[1] Rebagliati, et al. Funct Neurol, 2016. 31(3): 171-7.

[2] Mokkink, et al. COSMIN User Manual. 2018 